\title{
Re-establishment of Property Boundary using Geomatics Techniques
}

\author{
Audu, H.A.P. ${ }^{1, *}$ and Ekun, M.O. ${ }^{2}$ \\ ${ }^{1}$ Department of Civil Engineering, University of Benin, Benin City, Nigeria \\ ${ }^{2}$ Department of Geomatics, University of Benin, Benin City, Nigeria \\ Corresponding Author: *henry.audu@uniben.edu
}

\begin{abstract}
This study examined a parcel of land situated at Isheri-Olofin Community in Shomolu local government area of Lagos State whose boundary locations and lines have been obliterated with a view of re-establishing them to the required accuracy and standard using Geomatics techniques. The reconnaissance survey of the study area was carried out, and three (3) out of twenty (20) property boundary beacons were identified. The in situ check performed on the three beacons showed that they were in their original boundary locations. The three property beacons were used to relocate the positions of the remaining seventeen obliterated beacons using Geomatics instruments and conventional methods. The seventeen property beacons were re-established. In order to determine the accuracy of the re-established boundary beacons, a perimeter survey was carried out with a closed traverse method, and it commenced from three government control beacons which were within the study area. The in situ check of the three government control beacons was carried out prior to the commencement of the theodolite traversing. The acquired data were processed, the accuracy of the boundary survey was computed, the processed data was modelled using AutoCAD software and the property boundary plan was produced. The results of the study revealed that three of the property boundaries were in their original locations and seventeen (17) of them were obliterated. The obliterated property beacons in the study area were successfully re-established to the required standard and accuracy. The accuracy of the entire property boundary, which was within the allowable accuracy limits for $3^{\text {rd }}$ order traverse survey, was 1:56,470. This indicates that the obliterated beacons were re-established accurately, their boundary locations and lines were well defined. The property boundary plan, which shows the twenty boundary beacons and contains mathematical and documentary evidence for the property description of the study area was produced.
\end{abstract}

Keywords: Boundary survey, Boundary beacon, property description, beaconing, Survey standard

\subsection{Introduction}

Land forms a base for most human activity and is considered as the most essential of all resources. It is a basic, most valuable resource for every country. The modern concepts of sustainable development arising from fear of over-population, over-exploitation of resources and pollution, also reflect the view that land is a resource which must be preserved for future generations. These resources are limited and those that cannot be renewed should be satisfactorily controlled. This control can only be exercised by its accurate knowledge, description and record. Boundary (Cadastral) surveys are principal means of achieving these goals. Land availability, land resource, land use, land policy and management all have adverse effect on the socio-economic situation of any nation (Peter and Mclaughlin, 1988; Adedurin, 2005; Ehiorobo and Audu, 2010).

The existence of physical behavioural and territorial boundaries is essential for the societies to co-exist, manage property rights of individuals, organisations and the government; proper administrative division and management as well as define international boundaries. In the past, the definition of detailed individual boundaries was mainly used for delimitation of land property rights at the tribal and family level and for assessing land taxation. Internationally recognised and maintained boundaries of a state are an external expression of its stability and often reflect the state's internal strength and stability. They 
enable the development of the economy, trade and tourism with neighbouring states and are important for promoting collaboration regarding agriculture, environmental protection, taxation and national security. The establishment of new states has been the driving force for creating national and international boundaries. Furthermore, many international boundaries have been changed after wars. International boundaries of a state define the territorial limits of its sovereignty and the areas where its laws are applicable. In most developed countries, there is a great importance attached to the recognition and maintenance of international boundaries between states (Srebro and Israel, 2013).

There are a lot of challenges inherent in boundary locations. Improper or inadequate definition or delineation of boundary has resulted into quarrels, fights and even wars between adjacent communities, local governments and states. At the international level, boundary has resulted into full scale war, neighbouring countries annexing each other's town and occupying them (Adeaga, 1993). One of the indicators of underdevelopment is the number and magnitude of disputes and conflicts emanating from boundaries and boundaries demarcations. Boundary survey and boundary delimitations, marking and recording is a great instrument of dispute and conflict prevention (Obasanjo, 1993). Part of the challenges of boundary delimitations resulted from selection of insufficiently defined or unstable geographic features for describing natural boundary lines such as mountain crests, rivers, watersheds and deserts. Nowadays, Geomatics professionals are confronted with a multitude of problems created over the past two centuries under different technology and legal systems that now require professional solutions. These includes defective companies and chain surveys; incompatible description and plots of common lines of adjacent tracts; lost or obliterated corners and reference marks; discordant testimony by local residents and a tremendous number of legal decision on cases involving property boundaries (Ghilani and Wolf, 2012).

It has been observed that boundary beacons are deliberately or unknowingly tampered with by being displaced or removed completely. This practice has affected the government, individuals and surveyors in one way or the other. It has also led to many land-in-disputes, that have sometimes, resulted in loss of properties and lives (Ghilani and Wolf, 2012). It is clear that majority of the crises that occur in Nigeria and elsewhere in Africa are based on disputes over lands. Many of today's property disputes would have been avoided, if all property lines had been resurveyed, monuments checked and set before sales became final. Unfortunately, these beacons are often removed or displaced by some without knowing the reasons for burying them on the ground. Others sharpen their machetes or crack kernels on survey beacons without knowing that it is an offence (Didigwu, 2006). This practice, over time, may also lead to the displacement of such beacons. Unfortunately, millions of lives and properties have been lost to land disputes as a result of improper definition of boundaries.

The lack of clarity in defining international boundaries between states has been one of the main reasons for territorial disputes and ensuing wars. Such conflicts may arise because of economic interests (ownership of natural resources), national and ethnic reasons, or even religious beliefs. Unresolved disputes regarding boundary lines have potential for flaring up. They create friction even during calm periods, but when combined with other conflicts of interest between two neighbouring states, they may ignite a cross-boundary explosion (Srebro and Israel, 2013).

The objectives of this study are to: identify and determine the property beacons in the study area; determine the number of the beacons that were lost or obliterated and those that were not tampered with; carry out the in situ check on the existing boundary beacons, re-established the obliterated property beacons; determine the accuracy of the re-established property beacons ensuring they meet the required and acceptable accuracy as well as produced the property boundary(survey) plan of the landed property.

\subsection{Boundary (Cadastral) Surveys}

A boundary is a surface that divides one property or territory from another. It is also an imaginary line which marks the confines of two contiguous estates (Mohammed, 1993). A boundary surveys determines the property line of a parcel of land described in the deed. It indicates the extent of any easements or encroachments and may show the limitations imposed on the property by state or local regulations. The purpose of boundary surveys is to establish the boundary lines of a new parcel of land or to re-establish the boundary lines of an existing parcel of land. It allows the exact boundary and 
boundary lines of a land parcel to be accurately determined. A boundary survey is a useful tool when the location of the boundary line is in dispute, when making an addition to a home or improvement to a property, protecting against the laws of property to an outside party who wishes to gain legal interest in any land and when listing the property for sale (Scofield, 2001). Robertson (2013) viewed boundary making from four general phases, viz: preparation for a boundary agreement, boundary delimitation, boundary demarcation and boundary maintenance and administration. Mohammed (1993) opined that the techniques of boundary making which include three distinct and interrelated procedures are Boundary delimitation, demarcation and management. Isifeh and Asoegwu (1993) enumerated eight stages of boundary operations to include: delimitation, demarcation, survey, definition, mapping, delineation, maintenance and management. The first step of a professional surveyor that intends to restore a boundary, either a cadastral boundary or an international boundary, is to look for existing, authorized, preferably registered documentation. In the absence of a precise detailed documentation, existing boundary pillars, preferably accompanied by partial documentation, constitute the significant evidence (Srebro and Israel, 2013).

Ghilani and Wolf (2012) classified land (boundary) surveys into three categories, viz: original surveys, retracement surveys and subdivision surveys. The original surveys were used to survey and subdivide the remaining unsurveyed public lands. Retracement surveys were used to recover the monuments or mark boundary lines that were previously surveyed. They are run for the purpose of relocating or reestablishing previously surveyed boundary lines. The fundamental precept governing retracement surveys is that the monuments as originally placed and agreed to by the grantee and granter constitute the correct boundary location. The objective of retracement surveys therefore is to restore boundary markers (property beacons) to their original locations. Subdivision surveys were used to establish new smaller parcel of lands within lands already surveyed.

\subsection{Property Description}

Ghilani and Wolf (2012) enumerated the various methods of describing property as follows: metes and bound, block and lot system and coordinates.

\subsubsection{Property Description by Metes and Bounds}

Metes and bounds is one of the methods commonly used in preparing legal descriptions of property. They are included legal documents that accompany the transfer of title of property. Descriptions by metes (to measure, or assign by measure) and bounds (boundary lines or property lines) have a point of commencement (POC). The importance of permanent monuments to mark property is evident. To increase the precision in property surveys and to simplify the process of property descriptions and relocating the corners of established parcels, large cities and some states in developed and developing countries have established a network of control monuments through Geodetic surveying technique. These points are then available as control for initiating topographic and construction surveys and also serve as point of commencement (POC) for commencing property descriptions.

\subsubsection{Property Description by Block-and-Lot System}

As urban areas grow, adjoining parcels of land are subdivided to create streets, blocks and lots according to an orderly and specific plan. Each new subdivided parcel, called subdivision, is assigned a new name and annexed by City. Block and lot number, tract and lot number or subdivision name and lot's number identifies the individual lots within the subdivided area.

\subsubsection{Property Description by Coordinates}

Rectangular coordinates system provides a common reference system for surveys in large regions, even entire states. Several advantages result from using them on property surveys. One of the most significance is that they greatly facilitated in the relocation of lost and obliterated corners. Every monument (or property beacon) which has known coordinates becomes a "witness" to other corner makers whose positions are given in the same coordinate systems (Ghilani and Wolf, 2012). Rectangular coordinates also enable the evaluation of adjoiners with less field work. As cities and states develop, land information systems (LIS) and Geographic information system (GIS) description by coordinates are becoming the norm. Many local and statement governments in developed nation like 
USA and developing countries, like Nigeria, require coordinates on the corners of recorded subdivision boundaries and on the exteriors of large boundary surveys.

\subsection{Boundary Beacons}

A beacon is a permanent survey mark of any kind of concrete, iron or stone. Seedat et al.(2012) defined beacon as a natural or artificial feature which marks the boundary corner of a piece of land/property. It is the ground station of trigonometric point, permanent traverse picket and boundary post (Ofori-Boadu, 2006). It is buried at the corner or every change in direction of landed properties in order to define the shape and to provide a demarcation between adjacent properties according to survey regulations and making measurements both angular and linear to determine relative positions (Seedat et al, 2012; Land Survey Ordinance, 1997). This survey mark is very important in any survey operation because no survey can have lasting significance unless the marks placed is durable, stable, recognisable and situated for anticipated future use, as stated in the specifications of Department of Lands. Beacons are surveying tools that are also used to provide demarcation between adjacent landed properties. The construction and establishment of beacon is determined by the purpose of establishing it and the location of where it is being buried (Didigwu, 2006).

Geomatics beacons are established or buried on the ground as controls in which other survey projects are tied. Every survey has to start from a known or co-ordinated control point or benchmark in order for their surveys to be on the national co-ordinate system (Seedat et al, 2012). The duty of the Geomatics experts involve the emplacement of new marks, and the recording of their position for posterity, or the replacement of old marks which have disappeared and are required to be re-established from past records.

In each Surveyor General's office, there is always a safe section called Records and Archives, where all cadastral surveys that have been submitted to them by different Surveyors are kept. These records are used for beacon relocations and all other cadastral surveys to ensure that there is no possibility of properties overlapping as to avoid conflicting claims to ownership (Seedat et al., 2012). Survey standards are needed to provide quality assurance of accuracy. Survey standards defined the minimum accuracies deemed necessary to meet specific objectives (Doyle and Kozlowski, 2013). Doyle and Kozlowski (2013) and CALTRANS (2015) have classified the accuracy of horizontal and vertical controls into first, second, third and fourth orders. In establishing Geomatics beacons, the surveyor must strictly work in accordance to the approved survey standards, both legal and professional, for such survey (Ghilani and Wolf, 2012).

\subsection{Materials and Methods}

\subsection{The Study Area}

The study Area is located in Isheri-Olofin Community in Shomolu local government Area of Lagos state, Nigeria. It lies between the geographical extent of rectangular coordinates $733365.137 \mathrm{mN}-733$ $730.974 \mathrm{mN}$ and $542220.105 \mathrm{mE}-542847.245 \mathrm{mE}$ in Universal Transverse Mercator (UTM) origin, Lagos State. The satellite imagery which shows the study area is presented in Figure 1.

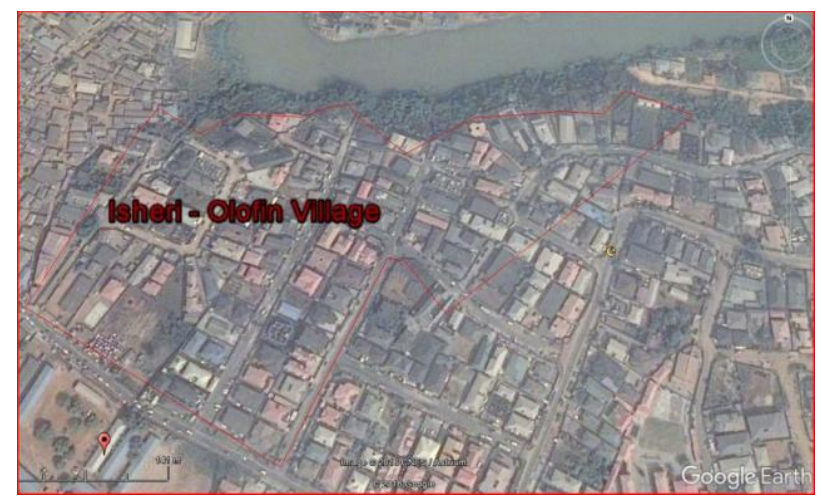

Figure 1: Satellite imagery showing Ikoro/Oshorun/Ikosi in Isheri Olofin Community (the study Area) (Source: Google Earth) 


\subsection{Data acquisition, processing, accuracy determination and modelling}

\subsubsection{Reconnaissance Survey and Data acquisition}

The reconnaissance survey was carried out in order to: identify the land parcel whose property beacons were obliterated and to familiarise with the site conditions; locate the existing beacons and the ones that have been lost/obliterated; locate the existing Government Control beacons to which the perimeter survey was tied; intimate the Surveyor General of the state; obtain the original boundary (Survey) plan and detailed documentation from OGIS Consult Ltd, Ikeja, Lagos, who did the original survey of the landed property in 1993, that facilitated the take-off of the project. Furthermore, pre-analysis of the entire study was carried out in order to determine the project components, equipment and methodology that would achieve the aim and objectives of the study, satisfy the required accuracy enshrined in the Surveyor's Council of Nigeria (SURCON) specifications for large scale, Cadastral and Engineering Surveying in Nigeria, as well as the Survey Rules and Regulations.

The Geomatics (land surveying) techniques, which include conventional Geomatics methods such as traversing (Nwilo,1998 ) was selected and employed in this project since it was not only apt for the set out task but also used originally for the boundary surveys. The Geomatics instrument used for angular measurement was theodolite. It was tested to ensure that the instrument was in good working condition, reliable and that the geometry of the instrument has not been altered or is within tolerance. The instrument was found to be in good working conditions and was therefore used for the field work in this study. A new steel tape was used for the linear measurements.

Three existing government control beacons, which were found in the area, were used for the connection survey. Out of the twenty (20) boundary beacons (pillars), only three (3) which were not removed are PAU 220, PAU 237, PAU 238. In line with survey regulation standard in Nigeria, angular and linear measurements were carried out on the three boundary beacons to ensure that they were in situ. The observed check angle and computed check angle gave a difference of some seconds of arc, while the difference between the measured and computed distance of the property beacons was in millimetres, confirming the in situ of the existing property beacons. The in situ check shows that the existing beacons were within the acceptable accuracy limits. The next task was to re-establish the seventeen (17) boundary beacons that have been obliterated. The external angles and distances between the three (3) contiguous pillars (PAU 220, PAU 237, PAU 238) were measured with the theodolite and steel tape and found to conform to the values obtained from the original survey. These sets of boundary beacons were subsequently adopted as the major controls for the study. The use of the three boundary beacons is in line with report of other researcher that every monument that its coordinates are known becomes a "witness" to other corner markers whose positions are given in the same system (Ghilani and Wolf, 2012). Using the obtained Survey plan and other relevant field notes from OGIS Consult Ltd, Ikeja, Lagos as a guide, the field work commenced from PAU 220 and working in a clockwise direction. The procedure include: tabulating the external angles and distances from the initial survey data; setting the theodolites on the known beacon; bisecting the preceding beacon as a reference and setting the horizontal circle to zero after the station adjustment; turning the telescope clockwise to set out the external angle to the beacon to be re-established; using the steel tape, the specified distance was pegged, bearing in mind to make allowance for the slope; burying of the established beacons and checking again for alignment and the distance. This procedure was repeated till all the seventeen (17) boundary beacons were re-established. Concrete beacons were used for beaconing for the re-established beacons.

In order to confirm and check the accuracy of the re-established boundary beacons, a traverse commenced from the government control beacons (MCS1145,MCS1144 and MCS1143) whose in situ was checked, and closed back on the same beacons. It was run in a clockwise direction. The existing features, which were mainly the existing road and river Ogun, were fixed taking offsets to them.

\subsubsection{Data processing and Analysis of the Accuracy}

The traverse survey was computed, the angular and linear accuracies were obtained. The Bowditch method was used for the adjustment of the coordinates. The rectangular coordinates of the twenty boundary beacons in this study were also obtained. 
In accordance with Surveyors Council of Nigeria (SURCON), the regulatory body of Surveying and Mapping in Nigeria, the specified angular accuracy (angular misclosure) limits for the third order traversing operations was calculated and determined with the following mathematical expressions (SURCON, 2003a):

$$
\text { Allowable Accuracy }(\mathrm{AA})=30, \sqrt{N}
$$

Where,

$\mathrm{N}=$ the number of the instrument station

The obtained angular accuracy computed from traverse survey using (1) was 22 second, while the maximum allowable angular accuracy was 134 seconds.

In line with (SURCON (2003a), the specified accuracy of the Survey (Linear misclosure) limit for the third order traversing operations was also calculated and determined using the following mathematical expressions (SURCON, 2003a)

$$
\text { Linear Accuracy }=\frac{\sqrt{(\Delta \mathrm{N})^{2}+(\Delta \mathrm{E})^{2}}}{\text { total distance }}
$$

Where,

$\Delta \mathrm{N}=$ Difference in the Northing Coordinates between two property beacons

$\Delta \mathrm{E}=$ Difference in the Easting Coordinates between two property beacons

\begin{tabular}{|c|c|c|}
\hline Aspect & Obtained Accuracy & Required Accuracy \\
\hline Angular Accuracy & 22 " for 20 stations & $\begin{array}{l}\text { Angular Accuarcy }=30, \sqrt{N} \\
=30 \% \sqrt{20} \\
=134 " \text { (Maximum) }\end{array}$ \\
\hline Linear Accuracy & $\begin{array}{l}\Delta \mathrm{N}=+0.012 \\
\Delta \mathrm{E}=+0.010 \\
\text { Total distance for the perimeter survey } \\
=1,710.170 \mathrm{~m}\end{array}$ & $\begin{array}{l}\text { Linear Accuracy }=\frac{\sqrt{(\Delta \mathrm{N})^{2}+(\Delta \mathrm{E})^{2}}}{\text { total distance }} \\
(\mathrm{SURCON}, 2003 \mathrm{a})\end{array}$ \\
\hline Linear Accuracy & 1: $56,469.75$ & 1: 3,000 (Minimum) \\
\hline
\end{tabular}

Table 1: Analysis of the Accuracy of the tertiary traverse survey

The accuracy of the traverse survey obtained for the study area was $1: 56,469.75$. The minimum allowable accuracy for the boundary traverse survey in Nigeria is 1: 3,000.

\subsubsection{Data Presentation}

The processed data were modelled using CAD (AutoCAD) software and the property boundary plan was produced.

\subsection{Results and Discussion}

\subsection{Results}

The summary of the coordinates of the property beacons whose boundary location and boundary lines were in situ is presented in Table 2. Table 3 shows the summary of the coordinates of the property beacons that were re-established. The summary of the coordinates of old and newly re-established property beacons is shown in Table 4, while Figure 2 shows the boundary (survey) plan of both the existing and re-established boundary beacons of the study area. 
Table 2: Summary of the planimetric coordinates of the property beacons not obliterated

\begin{tabular}{ccc}
\hline Beacon & \multicolumn{2}{c}{ Planimetric Coordinates } \\
& $\mathbf{N}(\mathbf{m})$ & $\mathbf{E}(\mathbf{m})$ \\
\hline PAU 220 & 733500.724 & 542220.102 \\
PAU 237 & 733544.009 & 542561.825 \\
PAU 238 & 733547.998 & 542545.423 \\
\hline
\end{tabular}

Table 3: Summary of the rectangular coordinates of the re-established property beacons

\begin{tabular}{ccc}
\hline Beacon & \multicolumn{2}{c}{ Planimetric Coordinates } \\
& $\mathbf{N}(\mathbf{m})$ & $\mathbf{E}(\mathbf{m})$ \\
\hline PAU 221 & 733680.938 & 542298.257 \\
PAU 222 & 733706.438 & 542314.157 \\
PAU 223 & 733679.021 & 542357.433 \\
PAU 224 & 733701.518 & 542391.446 \\
PAU 225 & 733699.086 & 542458.242 \\
PAU 226 & 733709.097 & 542483.041 \\
PAU 227 & 733713.587 & 542504.156 \\
PAU 228 & 733702.495 & 542509.355 \\
PAU 229 & 733655.981 & 542561.156 \\
PAU 230 & 733668.986 & 542583.044 \\
PAU 231 & 733695.978 & 542629.154 \\
PAU 232 & 733703.982 & 542716.147 \\
PAU 233 & 733701.028 & 542757.151 \\
PAU 234 & 733730.974 & 542783.140 \\
PAU 235 & 733701.956 & 542847.249 \\
PAU 236 & 733495.809 & 542597.423 \\
PAU 239 & 733365.137 & 542458.316 \\
\hline
\end{tabular}

Table 4: Summary of the coordinates of old and newly re-established property beacons

\begin{tabular}{ccccc}
\hline Beacon & New Coordinates of the Boundary Beacons & \multicolumn{2}{c}{$\begin{array}{c}\text { Old Coordinates of the Boundary } \\
\text { Beacons from the Original Surveys } \\
\text { N(m) }\end{array}$} & $\mathbf{E}(\mathbf{m})$ \\
\hline PAU 220 & $\mathbf{N}(\mathbf{m})$ & $\mathbf{E}(\mathbf{m})$ & 733500.719 & 542220.105 \\
PAU 221 & 733500.724 & 542220.102 & 733680.934 & 542298.253 \\
PAU 222 & 733680.938 & 542298.257 & 733706.433 & 542314.160 \\
PAU 223 & 733679.021 & 542314.157 & 733679.018 & 542357.428 \\
PAU 224 & 733701.518 & 542357.433 & 733701.519 & 542391.448 \\
PAU 225 & 733699.086 & 542458.242 & 733699.084 & 542458.241 \\
PAU 226 & 733709.987 & 542483.041 & 733709.985 & 542483.038 \\
PAU 227 & 733713.587 & 542504.156 & 733713.586 & 542504.154 \\
PAU 228 & 733702.495 & 542509.355 & 733702.497 & 542509.353 \\
PAU 229 & 733655.981 & 542561.156 & 733655.984 & 542561.158 \\
PAU 230 & 733668.986 & 542583.044 & 733668.985 & 542583.040 \\
PAU 231 & 733695.978 & 542629.154 & 733695.974 & 542629.157 \\
PAU 232 & 733703.982 & 542716.147 & 733703.986 & 542716.143 \\
PAU 233 & 733701.028 & 542757.151 & 733701.023 & 542757.155 \\
PAU 234 & 733730.974 & 542783.140 & 733730.971 & 542783.138 \\
PAU 235 & 733701.956 & 542847.249 & 733701.952 & 542847.245 \\
PAU 236 & 733495.809 & 542597.423 & 733495.804 & 542597.420 \\
PAU 237 & 733544.009 & 542561.825 & 733544.006 & 542561.822 \\
PAU 238 & 733547.998 & 542597.423 & 733547.995 & 542545.427 \\
PAU 239 & 733365.137 & 542458.316 & 733365.133 & 542458.312 \\
\hline
\end{tabular}




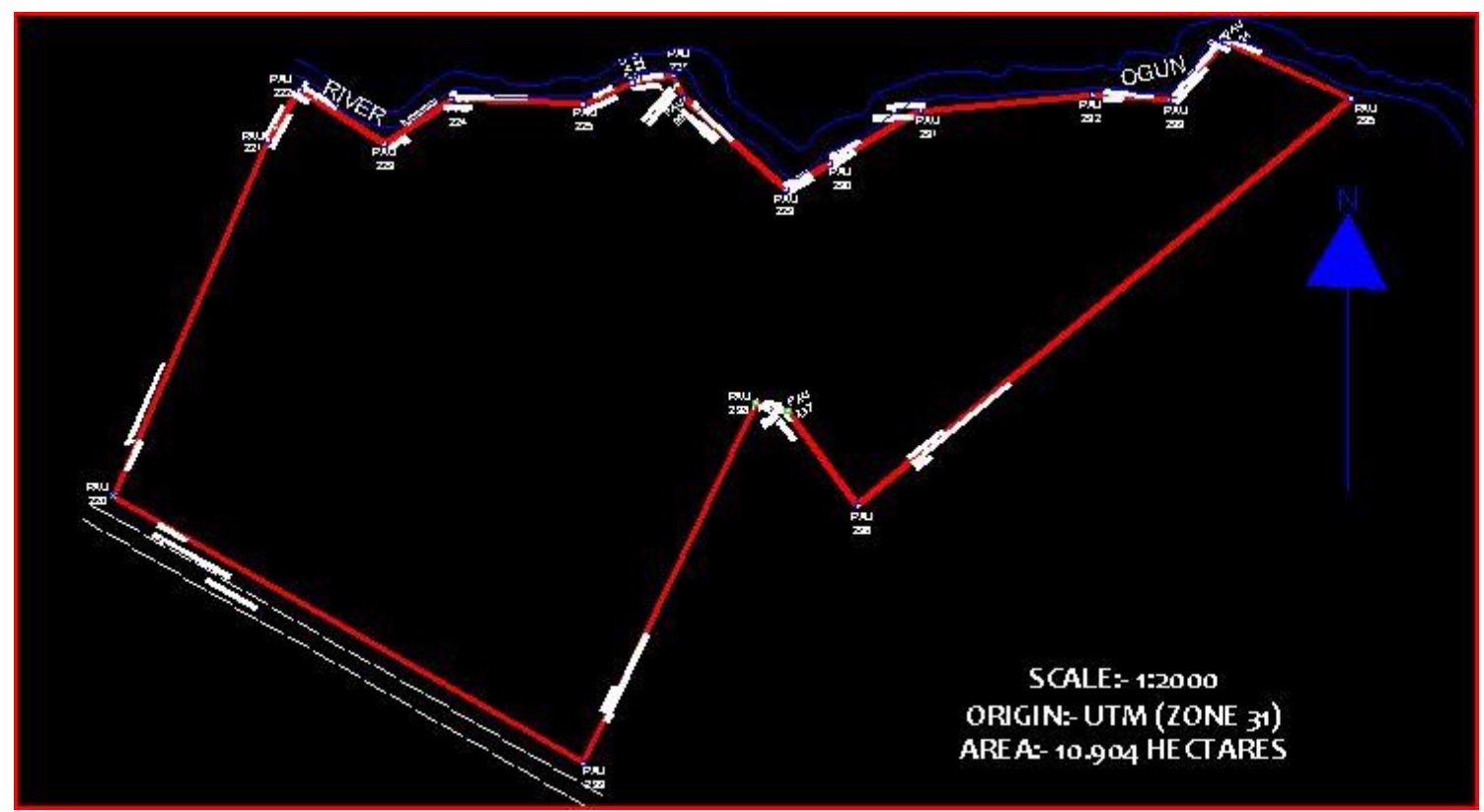

Figure 2: Boundary (Survey) Plan of the study Area

\subsection{Discussion}

The coordinates shown in Table 2 together with their property beacons, boundary locations and boundary lines were not tampered with. The in situ check carried out in this study has shown that property beacons PAU 220, PAU 237 and PAU 238 maintained their original location. According to Ghilani and Wolf (2012), property beacon whose coordinates were accurately known serves as a witness to the other property beacons since their positions are given in the same coordinate system. Therefore, the above three beacons whose coordinates were accurately known serve as witnesses to the other property beacons in the study area since their positions are given in the same coordinate system. The rectangular coordinates (shown in Tables 2 and 3) are the most convenient and most used method of describing the positions of spatial objects (Audu and Ehiorobo, 2010; Audu and Ukeme, 2013 and Audu and Ehiorobo, 2015).

The accuracy of the survey of the re-established property beacons in Table 1 was $1: 56,470$ and the angular accuracy obtained was twenty-two seconds (22"). These accuracies obtained were within the allowable accuracy limits for tertiary traversing and Cadastral (boundary) surveys in Nigeria. The coordinates of the re-established beacons will not only serve as common reference system for the property survey but shall also facilitate the relocation of lost and obliterated corners of the land parcel. This confirms the report of Ghilani and Wolf (2012). The obtained accuracy for the seventeen obliterated beacons shows that the beacons were not only re-established accurately, but also that their boundary locations and their boundary lines were well defined.

The analysis of the coordinates in Table 4 of the re-established and original property beacons obtained from the original surveys shows some differences ranging from 1-5 millimetres in the both the Northing and Easting coordinates. These values fall within the permissible accuracy limits.

The

property boundary (survey) plan in Fig. 2 is a graphic representation of the parcel boundary, which also shows the boundary locations and the boundary lines of the re-established property boundary beacons. The plan contains mathematical and documentary evidence for property description in the study area.

\subsection{Conclusion}

The study has identified the obliterated property beacons, re-surveyed them with Geomatics instruments and techniques. The boundary markers (property monuments) were re-established to their original locations. The accuracy of the boundary traverse survey, which was carried out as a check after the reestablishment of the obliterated beacons, and in accordance with the rules and regulations governing the boundary(cadastral) survey in Nigeria, falls within the permissive accuracy (misclosure) for such 
survey. This therefore implies that the seventeen (17) obliterated beacons were not only re-established accurately, but also that their boundary locations and their boundary lines were well defined.

The set objectives of the study were achieved. Moreover, this study has also shown the immense role that Geomatics techniques and instruments of the Geomatics Engineers played in property boundary reestablishment and property boundary maintenance for peaceful co-existence of communities and socioeconomic development of any nation.

\section{Acknowledgement}

The authors are grateful to OGIS Consult Ltd, Ikeja, Lagos for her immense role during this study and the opportunity to obtain relevant information from her Geomatics Database.

\section{References}

Adedurin, I. O. (2005), "Land procurement, Management, Information and Surveying in Nigeria, First Edition, published by Peterseg Integrated Ltd, Lagos, Nigeria, 145pp

Audu, H.A.P. and Ehiorobo, J. O. (2010), "Location and Geospatial Positioning of Water Distribution Infrastructure in GIS Environment" Technical Transactions, Journal of the Nigerian Institution of Production Engineers, Benin City, Vol. 12, pp 65-79

Audu, H.A.P and Ukeme, U. (2013), "Geo-spatial Information for the Location and Maintenance Management of Water Service Pipelines", Journal of Advanced Materials Research, Trans Tech publications, Zurich, Switzerland, Vol. 824, pp 635-642

Audu, H.A.P. and Ehiorobo, J.O. (2015), “Geospatial Techniques in Water Distribution Network Mapping and Modelling in Warri Port Complex (Nigeria), Published by International Federation of Surveyors (FIG), http//www.fig.net/resources/proceedings/fig_proceeding/ fig2015/ papers/ts07d /Ts0 7D_audu_ehiorobo_7663_abs.pdf

California Department of Transportation (CALTRANS) (2015) "Classifications of Accuracy and Standards" Survey Manual, 2015

Dale, P.F. and Mclaughlin, J.D. (1988), "Land information Management: An introduction with special reference to Cadastral problems in $3^{\text {rd }}$ World counties", Clarendon press, Oxford, 266pp.

Didigwu, A. U. S. (2006) "The consequences of destroying Survey Beacons by the African Public - A Case Study of Nigeria" 5th FIG Regional Conference, Published by International Federation of Surveyors (FIG)

Doyle, D.and Kozlowski, J. (2013) "FGDC Accuracy Standards" New Jersey Society of Professional Land Surveyors, Atlantic City

Ehiorobo, J.O. and Audu, H.A.P. (2010), "Technical and Legal Issues in Land Acquisition and Natural Gas Facilities within the Niger Delta Region of Nigeria", Published by International Federation of Surveyors (FIG).

Ghilani, C. D. and Wolf, P. R. (2012) "Elementary Surveying - An Introduction to Geomatics" 13th Edition, Pearson Education Inc, New Jersey, 983pp

Isifeh,C. C. and Asoegwu, R.N. (1993) "On the enhancement of field operations for Nigerian inter-state boundary definitions", the proceedings of the Nigerian Institution of Surveyors (NIS) of the $28^{\text {th }}$ Annual General Meeting and Conference of , held at the Gateway Hotel, Abeokuta, $13^{\text {th }}-16^{\text {th }}$ April, 1993.

Land Survey Ordinance (2009) "Revised Edition of Land Survey Ordinance and Subsidiary Legislation of 1997", Chapter 9.03, Crown Copyright, 2009 www.lawrevision.ai, accessed on $1^{\text {st }}$ August 2016.

Mohammed, A. S. A. (1993), "Boundary making in Nigeria: the solicited role of the surveyor", The proceedings of the Nigerian Institution of Surveyors (NIS) of the $28^{\text {th }}$ Annual General Meeting and Conference, held at the Gateway Hotel, Abeokuta, $13^{\text {th }}-16^{\text {th }}$ April, 1993. 
Nwilo, P.C. (1998), "Data acquisition by ground survey methods: Principles and Applications of Geographic Information Systems", Series in Surveying and Geoinformatics, University of Lagos, pp 105-121.

Obasanjo, O. (1993) “The Surveyors and Nigeria's boundaries, key note address at the $28^{\text {th }}$ Annual

General Meeting and Conference, held at the Gateway Hotel, Abeokuta.

Ofori-Boadu, J. (2006) "Standards in Ghana" 5th FIG Regional Conference, Ghana published by International Federation of Surveyors (FIG)

Robertson, B. (2013) "International boundary making: professional standards and practice", FIG Commission 1, No 59, Published by International Federation of Surveyors (FIG)

Schofield, W. (2001), Engineering Surveying, $5^{\text {th }}$ edition, published by Butterworth Heinemann, Oxford, Great Britain

Seedat, M.; Thusi, S.. Zaca, M. Mnembe, L. Ndaba, N. (2012),"Different Methods of Surveying", Survey and Land Information Department

Srebro, H. and Israel, M. S. (2013), "The order of precedence of boundary definition", published by International Federation of Surveyors (FIG), Commission 1, No 59 